\title{
Measurement uncertainty evaluation of automatic Tan Delta and resistivity test set for transformer oil
}

\author{
N.K. Mandavgade ${ }^{1, \star}$, S.B. Jaju ${ }^{2}$, and R.R. Lakhe ${ }^{3}$ \\ 1 Research Schoolar, G.H. Raisoni College of Engg, Nagpur, Maharashtra, India \\ 2 Professor, G.H. Raisoni College of Engg, Nagpur, Maharashtra, India \\ 3 Director Shreyas Quality Management System, Nagpur, Maharashtra, India
}

Received: 22 February 2012 / Accepted: 24 March 2012

\begin{abstract}
Quality of transformer oil plays vital role in the performance of transformer in electrical appliances. Measurement uncertainty is a general concept associated with any measurement and can be used in professional decision processes as well as judging attributes in many domains, both theoretical and experimental. As the tolerances applied in industrial production become more demanding, the role of measurement uncertainty becomes more important when assessing conformity to these tolerances. Measurement uncertainty plays a central role in quality assessment and quality standards. In an effort to meet national, international and commercial accreditation requirements, users of transformer oil testing machines must establish adequate methods of determining calibration and test measurement uncertainties. Determining measurement uncertainty for transformer oil testing equipments and test data can be a very complex process. Many factors affect the uncertainty of test data produced by testing machines. In this paper, the concepts associated with the procedure for estimation of uncertainty is discussed and the application of these for the determination of uncertainty in transformer oil testing equipments in government testing labs is illustrated. The objective of this study is to develop a methodology for determining the result of measurement concerning electrical properties of transformer oil and their respective uncertainties.
\end{abstract}

Keywords: Resistivity; Tan Delta; transformer oil; accuracy; uncertainty of measurement

\section{Introduction}

In dealing with the various firms that perform laboratory testing of transformer oil samples, there are different recommended tests and different threshold levels associated with the results. Therefore, it might be useful to discuss what is consider to be the more useful tests that need to be performed and the acceptable results associated with those tests. It is highly recommended that transformer oil sample tests to be performed at least on an annual basis with results compared from year to year. Transformer oil sample tests can be separated into two general categories, those that assess the immediate acceptability of the insulation system and those that assess the degree of aging or degradation of the insulation system. Electrical properties of the insulating system change due to age and continuous electrical stress [1]. The principal contributor to the unexpected breakdown of the high voltage equipment is the insulation failure. As compared to the magnetic, conducting and insulating materials which form the basics of any electrical equipment, the insulating material is more prone to service stresses like thermal stress, electrical stress, mechanicals stress, environmental stress, etc.

^ Correspondence: nitin_man@rediffmail.com
By measuring the electrical properties such as capacitance and Tan-Delta regularly on periodical basis, it is possible to ensure the operational unexpected breakdown. Dissipation factor (Tan-Delta) is one of the most powerful offline non destructive diagnostic tools to monitor the condition of solid insulation of various high voltage equipment. There are several reasons due to which Tan Delta value may be affected-moisture, dissolving of some of the transformer varnish, insulating material deteoriating, etc.

\subsection{Description}

The automatic Tan Delta and resistivity test set has been specially designed to determine the Tan Delta and resistivity of transformer oil and other electrical insulating liquids using a guarded three terminal test cell. This may also be used for measurement of the above parameters of solid insulating materials using a guarded three terminal solid test cell. There are built-in safety features which include zero start on voltage adjustment, auto trip with LED indication if two grounds are not connected; auto trip with LED indication if safeties interlock is opened $[2,3]$.

The $\epsilon$ (epsilon) - DF portion of the instrument operates as a manually balanced capacitance bridge. Since $\epsilon$ is 
Table 1. Specification of Tan Delta and resistivity set.

\begin{tabular}{|c|c|}
\hline $\begin{array}{l}\text { Ranges } \\
\text { Tan Delta } \\
\text { Resistivity }\end{array}$ & $\begin{array}{l}10^{-5} \text { to } 10 \\
\text { From } 10^{9} \text { to } 10^{15} \Omega \mathrm{cm}\end{array}$ \\
\hline \multicolumn{2}{|l|}{ Accuracy } \\
\hline Tan Delta & $\pm 0.01 \%$ \\
\hline Resistivity & $\pm 2 \%$ \\
\hline \multicolumn{2}{|l|}{ Resolution } \\
\hline \multirow[t]{4}{*}{ Tan Delta } & 0.00001 in $10^{-5}$ range \\
\hline & 0.0001 in $10^{-4}$ range \\
\hline & 0.001 in $10^{-3}$ range \\
\hline & 0.01 in $10^{-2}$ range \\
\hline Resistivity & 0.01 of each range \\
\hline Cell constant $(\mathrm{cm})$ & $\begin{array}{l}3 \text { digit adjustment for Tan Delta zero and capacitance. } \\
\text { Any cell or test fixture between } 50-70 \mathrm{pF} \text { can be used. }\end{array}$ \\
\hline Test voltage & Internally generated with accuracy $\pm 1 \%$ \\
\hline Tan Delta & $(0-1000 \mathrm{~V}$ and $0-3000 \mathrm{~V})$ \\
\hline Resistivity & $+500 \mathrm{~V}$ DC-Fixed \\
\hline Power supply & $230 \mathrm{VAC} \pm 10 \%, 50 \mathrm{~Hz}$, or $110 \mathrm{~V} \mathrm{AC} \pm 10 \%, 60 \mathrm{~Hz}, 150 \mathrm{VA}$ \\
\hline Temperature range & $-10{ }^{\circ} \mathrm{C}$ to $50{ }^{\circ} \mathrm{C}$ \\
\hline Humidity & Ambient to $90 \% \mathrm{RH}$ \\
\hline Dimension & 19 standard racks mount chassis \\
\hline Weight & Approx. $17 \mathrm{~kg}$ \\
\hline
\end{tabular}

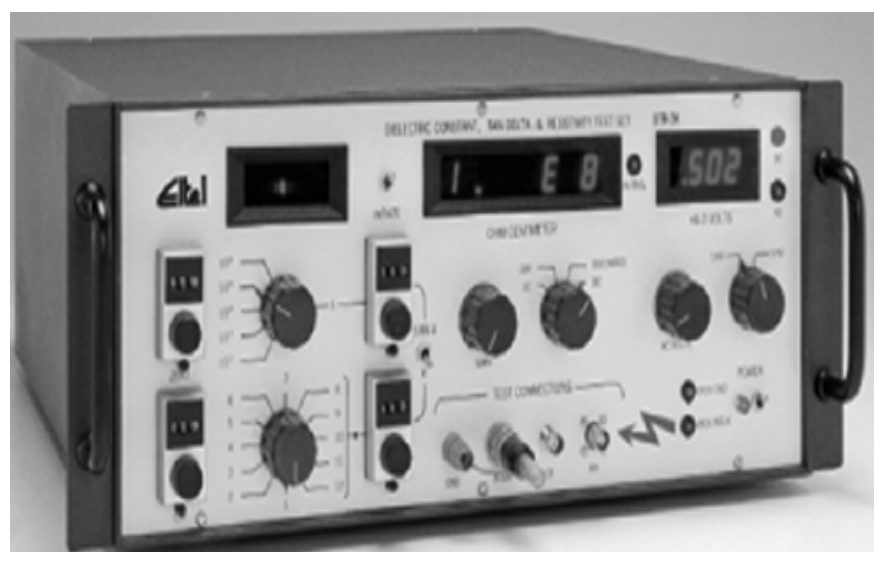

Fig. 1. Tan Delta test cell.

ratio of the full cell capacitance to the empty cell capacitance (in $\mathrm{cm}$ ) must be dialed in or be balanced out by using the balancing procedure. The cell constant (in $\mathrm{cm}$ ) equals $3.6 \times \pi \times 1 \times C$, where $C$ is the cell capacitance in $\mathrm{pF}$. The bridge balance is accomplished with the aid of synchronous and phase sensitive null detector which allows easy and independent balancing of the $\epsilon$ and DF components. The $\epsilon-\mathrm{DF}$ tests are carried out with respect to line frequency [2].

The resistivity meter is auto ranging with the reading displayed on $3^{1 / 2}$ digits DPM. Once the cell constant is balanced with the $\mathrm{cm}$ dial, the resistivity meter reads volume resistivity directly in ohm-centimeters. With the $\mathrm{cm}$ dial set to 1000 , the resistivity meter reads resistance in ohms multiplied by a factor of 1000 . The auto ranging feature eliminates the need for selecting the right range
Table 2. Specifications of Oil Test Cell Heater.

\begin{tabular}{lc}
\hline Power supply & $230 \mathrm{~V} \mathrm{AC} \pm 10 \%, 50 \mathrm{~Hz}$ or $110 \mathrm{~V}$ \\
$200 \mathrm{VA}$ & $\mathrm{AC} \pm 10 \%, 60 \mathrm{~Hz}$, \\
\hline Temperature range & $20-110{ }^{\circ} \mathrm{C}$ \\
\hline $\begin{array}{l}\text { Accuracy of } \\
\text { temperature control }\end{array}$ & $\pm 2{ }^{\circ} \mathrm{C}$ \\
\hline Dimension & $310 \times 190 \times 300 \mathrm{~mm}$ \\
\hline Weight & Approx. $12 \mathrm{~kg}$ \\
\hline
\end{tabular}

manually. Refer Figure 1. The specifications of Tan Delta and resistivity set are as shown in Table 1.

\subsection{Essential accessories}

\subsubsection{Oil Test Cell Heater}

The Oil Test Cell Heater OCH-85 Figure 2 is a very compact unit and is used to heat the oil in the cell to the required temperature. This uses high frequency induction heating which raises the temperature to $90{ }^{\circ} \mathrm{C}$ in 15 min approximately. A knob and a dial are provided to set the temperature at required level. A temperature sensing probe is supplied and this senses the temperature and stops heating the oil once the set temperature is reached. Two LEDs are provided to indicate 'heating on' and 'heating off'. To ensure safety the built-in micro switch interlock automatically trips out the high voltage when the plexi cover of the heater is raised. Refer Figures 2 and 3. The specification of oil test cell heater is as shown in Table 2. 


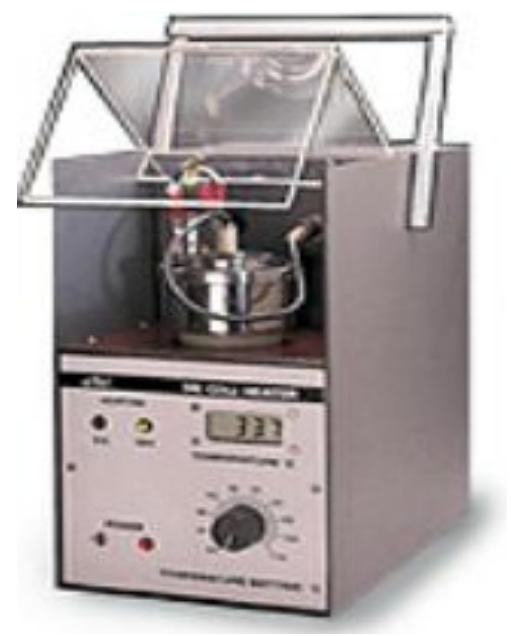

Fig. 2. (Color online) Oil Test Cell Heater.

Table 3. Specification of Oil Test Cell.

\begin{tabular}{lc}
\hline Construction & 3 terminal configurations \\
\hline Material & $\begin{array}{c}\text { Stainless Steel Body (SS 316) } \\
\text { with Teflon spacers }\end{array}$ \\
\hline Capacitance & $50-70 \mathrm{pF}$ \\
\hline Electrode spacing & $2 \mathrm{~mm}$ \\
\hline Volume & $45 \mathrm{ml}$ \\
\hline Dimension & $90 \times 185 \mathrm{~mm}$ \\
\hline Weight & Approx. $2.5 \mathrm{~kg}$ \\
\hline
\end{tabular}

\subsubsection{Oil Test Cell}

This three Terminal Oil Test Cell Figure 4 is designed for routine and laboratory Tan Delta tests on transformer oils and other electrical insulating liquids. The electrode of the cell is designed with a spherical bottom which offers more uniform stress on the oil as compared to electrode with tapered end. The specification of oil test cell is as shown in Table 3.

\subsubsection{C-Df and resistivity calibrator}

This calibration box Figure 5 is used to routinely check and inspect the test set. The portable calibrator offers one capacitance, three Tan Delta and four resistivity values. The maximum operating voltage is $500 \mathrm{v}$ AC/DC.

\subsubsection{Principle of working}

Automatic Tan Delta and resistivity test set is an automated instrument for measuring the electrical characteristics of transformer oil, insulating liquids and other insulating material samples. The Tan Delta test works on

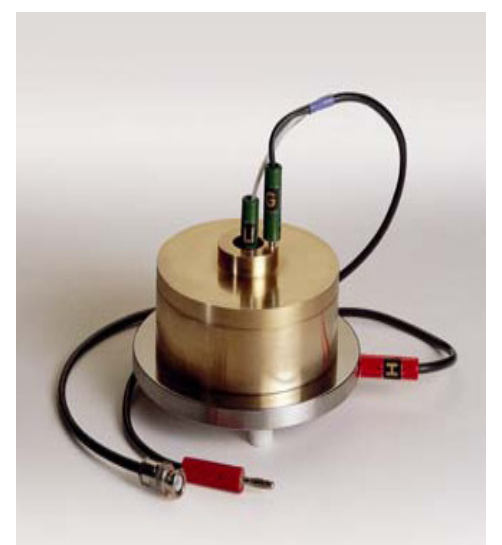

Fig. 3. (Color online) Solid test cell.

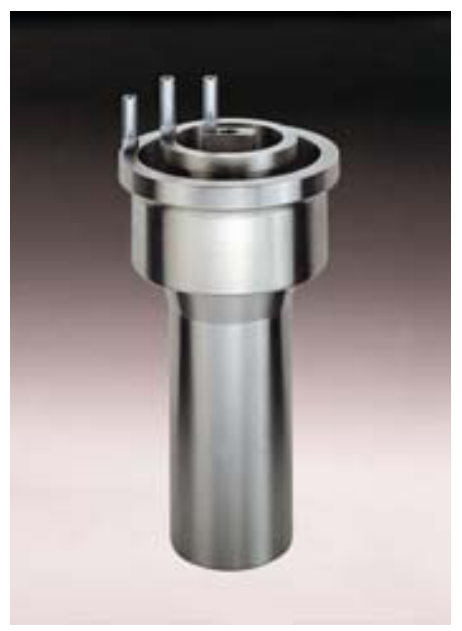

Fig. 4. Oil Test Cell.

the principle that any insulation in its pure state acts as a capacitor. The test involves applying a very low frequency $\mathrm{AC}$ voltage. A low frequency causes a higher value of capacitive reactance which leads to lesser power requirement during the test. Besides, the currents will be limited enabling easier measurement. In a pure capacitor, the current is ahead of the voltage by 90 degrees. The insulation, in a pure condition, will behave similarly. However, if the insulation has deteriorated due to the entry of dirt and moisture, the current which flows through the insulation will also have a resistive component. This will cause the angle of the current to be less than 90 degrees. This difference in the angle is known as the loss angle. The tangent of the angle which is $\mathrm{Ir} / \mathrm{Ic}$ (opposite/adjacent) gives us an indication of the condition of the insulation. A higher value for the loss angle indicates a high degree of contamination of the insulation references $[2,3]$ Figure 6 .

\section{Evaluation of uncertainty}

In case of transformer oil testing, we have performed number of test for each parameter. Two types of uncertainties are associated with each measuring parameters. 


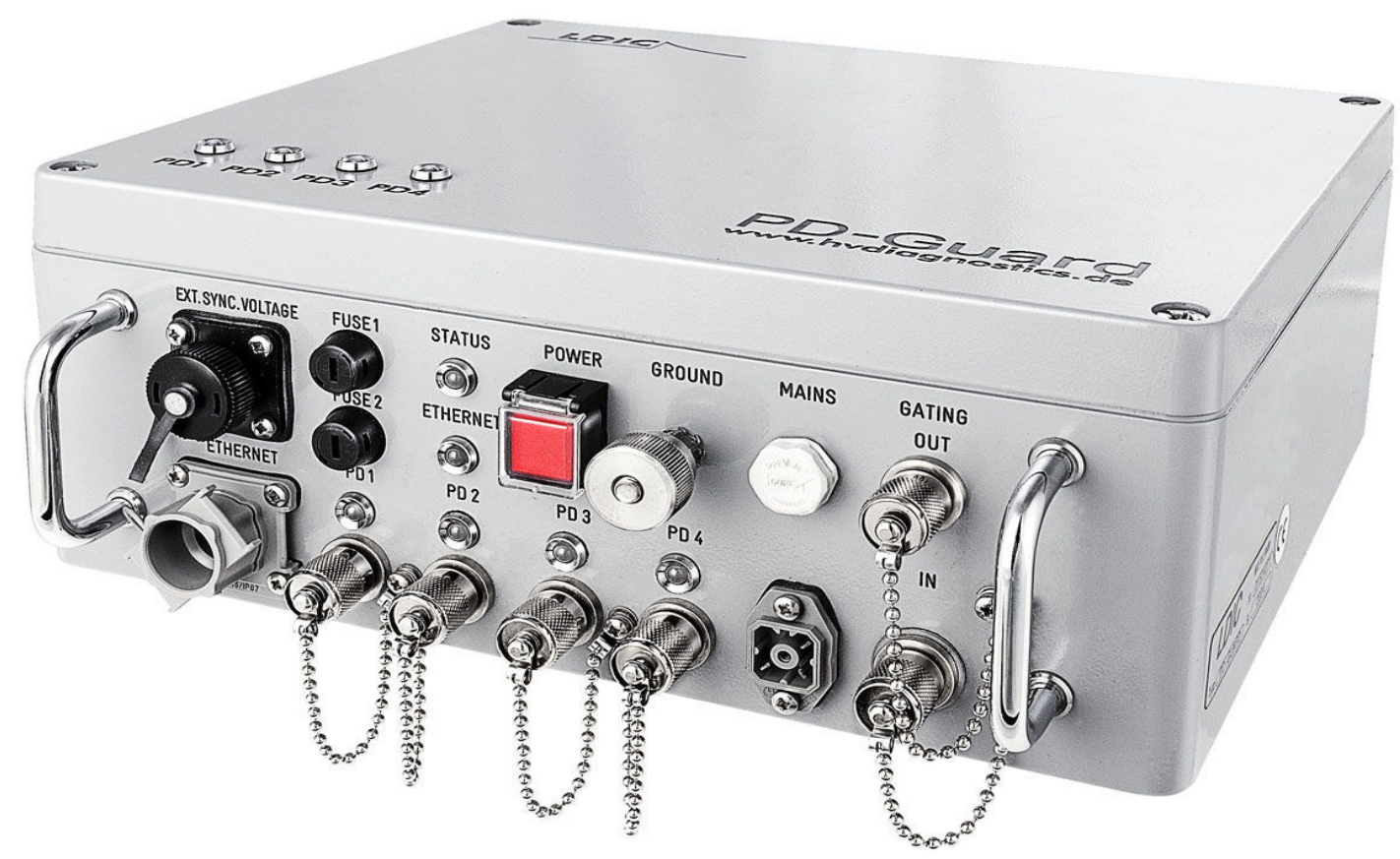

Fig. 5. (Color online) Calibrator.

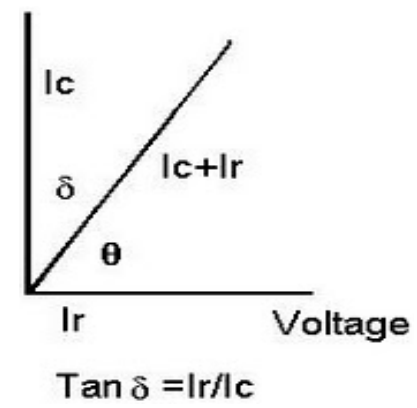

Fig. 6. Principle of working.

To calculate uncertainty following steps are to be followed $[4,5]$ :

Step 1. Specify measurand, express mathematically the equation relating measurand and input quantities. Identify all uncertainty sources.

Step 2. Determine the input quantities.

Step 3. Quantify the standard uncertainties of all single components.

Step 4. Identify the covariance (of correlated input quantities).

Step 5. Calculate the result of the measurement from the input quantities.

Step 6. Calculate the combined uncertainty.

Step 7. Calculate the expanded uncertainty.

Step 8. Give the result together with the uncertainty as estimated.
The combined uncertainty is given by equation (1).

$$
U_{c}=\sqrt{U_{A}^{2}+U_{B 1}^{2}+U_{B 2}^{2}+\ldots+U_{B n}^{2}}
$$

where:

$U_{A}=$ type-A standard uncertainty;

$U_{B}=$ type-B standard uncertainty.

\subsection{Methodology of selecting factors}

The factors are selected based on analytical data, calibration certificates, past experience and results at interlab testing as below $[6,7]$.

\subsubsection{Repeatability}

It is included in type-A uncertainty. It is an analytical method including the calculation of standard deviation and type-A standard uncertainty. Standard deviation indicates the spread of values which tells us something about the uncertainty of measurement [2].

\subsubsection{Accuracy of reading}

Least count of scale, slight fluctuations of reading are considered in type-B uncertainty. The uncertainty contributed by this factor affects the final result. So their considerations are must. 
Table 4. Reading of Tan Delta.

\begin{tabular}{ccccccccccc}
\hline Sr. No. & 1 & 2 & 3 & 4 & 5 & 6 & 7 & 8 & 9 & 10 \\
\hline$X i$ value & 0.00733 & 0.00740 & 0.00773 & 0.00766 & 0.00792 & 0.00792 & 0.00748 & 0.00733 & 0.00740 & 0.00773 \\
\hline
\end{tabular}

Table 5. Uncertainty budget.

\begin{tabular}{|c|c|c|c|c|c|}
\hline Sources & $\begin{array}{c}\text { Probability } \\
\text { type A or type B }\end{array}$ & Std uncertainty MPa & $\begin{array}{l}\text { Sensitivity } \\
\text { coefficient }\end{array}$ & $\begin{array}{l}\text { Uncertainty } \\
\text { contribution }\end{array}$ & DOF \\
\hline$U_{1}=$ Repeatability & Normal, type A & 0.000073 & 1 & 0.000073 & 9 \\
\hline$U_{2}=$ Accuracy of reading & Rectangular type B & 0.000057 & 1 & 0.000057 & $\infty$ \\
\hline$U_{3}=$ Accuracy of test voltage & Rectangular type B & 0.00577 & 1 & 0.00577 & $\infty$ \\
\hline$U_{4}=$ Calibration of capacitor & Rectangular type B & 0.00076 & 1 & 0.00076 & $\infty$ \\
\hline Expanded uncertainty & $K=1.96$ & & & \pm 0.01140 & \\
\hline
\end{tabular}

Table 6. Resistivity value.

\begin{tabular}{ccccccccccc}
\hline Sr. No. & 1 & 2 & 3 & 4 & 5 & 6 & 7 & 8 & 9 & 10 \\
\hline$X i \times 10^{12}$ & 20.46 & 21.72 & 18.61 & 19.06 & 18.18 & 16.66 & 21.55 & 20.46 & 21.72 & 18.61 \\
\hline
\end{tabular}

\subsubsection{Accuracy of test voltage}

In both the tests, proper test voltage is set. The test voltage has its accuracy mentioned in technical specification. Using this value standard uncertainty is calculated. This uncertainty value has a major contribution in final result.

\subsubsection{Calibration of capacitor and resistor}

Calibration of instrument and its components play an important role in calculating uncertainty of measurement. Calibration of instrument has an uncertainty which is consider into the uncertainty of the measurement.

\section{Result}

The test is performed with same operator and same equipment for testing the quality parameters of transformer oil in term of Tan Delta value and resistivity for ten times and observations are as shown below.

\subsection{Uncertainty of measurement of Tan Delta}

Observation - Refer Table 4

Mean $=x=0.00759$.

Standard deviation $=2.31 \times 10^{-4}$

Standard uncertainty $=U_{1}=0.000073$.

$\mathrm{DOF}=n-1$ ( $n=$ number of readings $)$.

Accuracy of reading $= \pm 0.01 \%=0.0001$ (mentioned in technical specification).

Standard uncertainty $=U_{2}=5.7 \times 10^{-5}$.

Accuracy of test voltage $= \pm 1 \%=0.01$ (mentioned in technical specification).

Standard uncertainty $=U_{3}=0.00577$.

Calibration uncertainty of capacitor $= \pm 0.15 \%=0.0015$, at $K=1.96$ (mentioned on calibration certificate).
Standard uncertainty $=U_{4}=0.0015 \div 1.96=0.00076$.

Combined uncertainty $=U_{C}$

$$
\begin{aligned}
& =\sqrt{0.000073^{2}+0.000057^{2}+0.00577^{2}+0.00076^{2}} \\
& =0.00582 .
\end{aligned}
$$

Effective degree of freedom,

$$
V_{e f f}=\frac{U_{C}^{4}}{\frac{U_{1}^{4}}{9}+\frac{U_{2}^{4}}{\infty}+\frac{U_{3}^{4}}{\infty}+\frac{U_{4}^{4}}{\infty}}=\infty .
$$

Then coverage factor $(K)$ for $U_{\text {eff }}=\infty$ at level of confidence of approximately $95 \%, K=1.96$.

Expanded uncertainty $=0.00582 \times 1.96= \pm 0.01140$.

Final result $-0.00759 \pm 0.01140$.

Uncertainty Budget - Refer Table 5 .

Uncertainty contribution - Refer Figure 7.

\subsection{Uncertainty of measurement of resistivity}

Observation - Refer Table 6

Mean $=x=19.703 \times 10^{12}$.

Standard deviation $=1.734 \times 10^{12}$.

Standard uncertainty $=U_{1}=0.5483 \times 10^{12}$

$\mathrm{DOF}=n-1=9$ ( $n=$ number of readings $)$.

Accuracy of reading $= \pm 2 \%=0.02$ (mentioned in technical specification).

Standard uncertainty $U_{2}=0.01154$.

Accuracy of test voltage $= \pm 1 \%=0.01$ (mentioned in technical specification).

Standard uncertainty $=U_{3}=0.00577$.

Calibration uncertainty of resistor $= \pm 0.02 \%=0.0002$.

Standard uncertainty $=U_{4}=0.00010$. $(K=1.96)$, $\mathrm{DOF}=\infty$.

Combined uncertainty $=U_{C}$

$$
=\sqrt{\left(0.5483 \times 10^{12}\right)^{2}+0.01154^{2}+0.00577^{2}+0.00010^{2}} .
$$

Effective degree of freedom $=\frac{U_{C}^{4}}{\frac{U_{1}^{4}}{9}+\frac{U_{2}^{4}}{\infty}+\frac{U_{3}^{4}}{\infty}+\frac{U_{4}^{4}}{\infty}}=\infty$. 


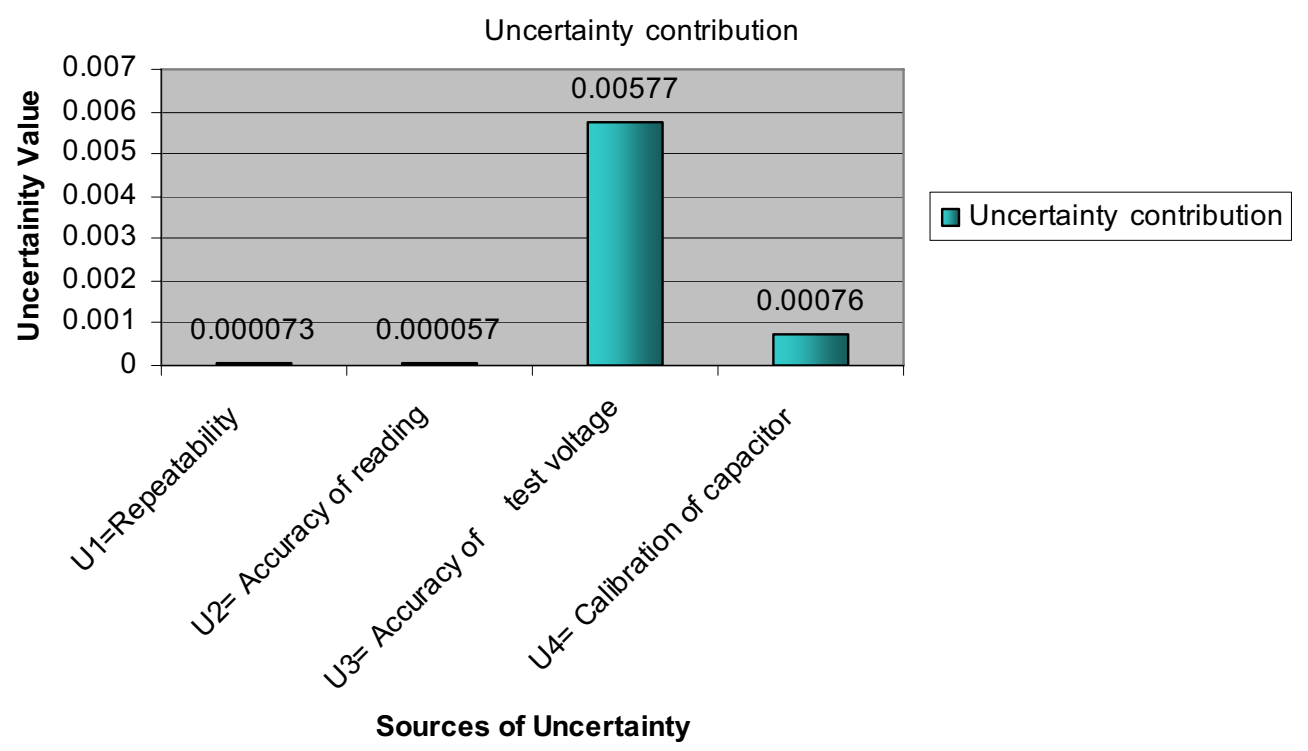

Fig. 7. (Color online) Effects of various factors for Tan Delta.

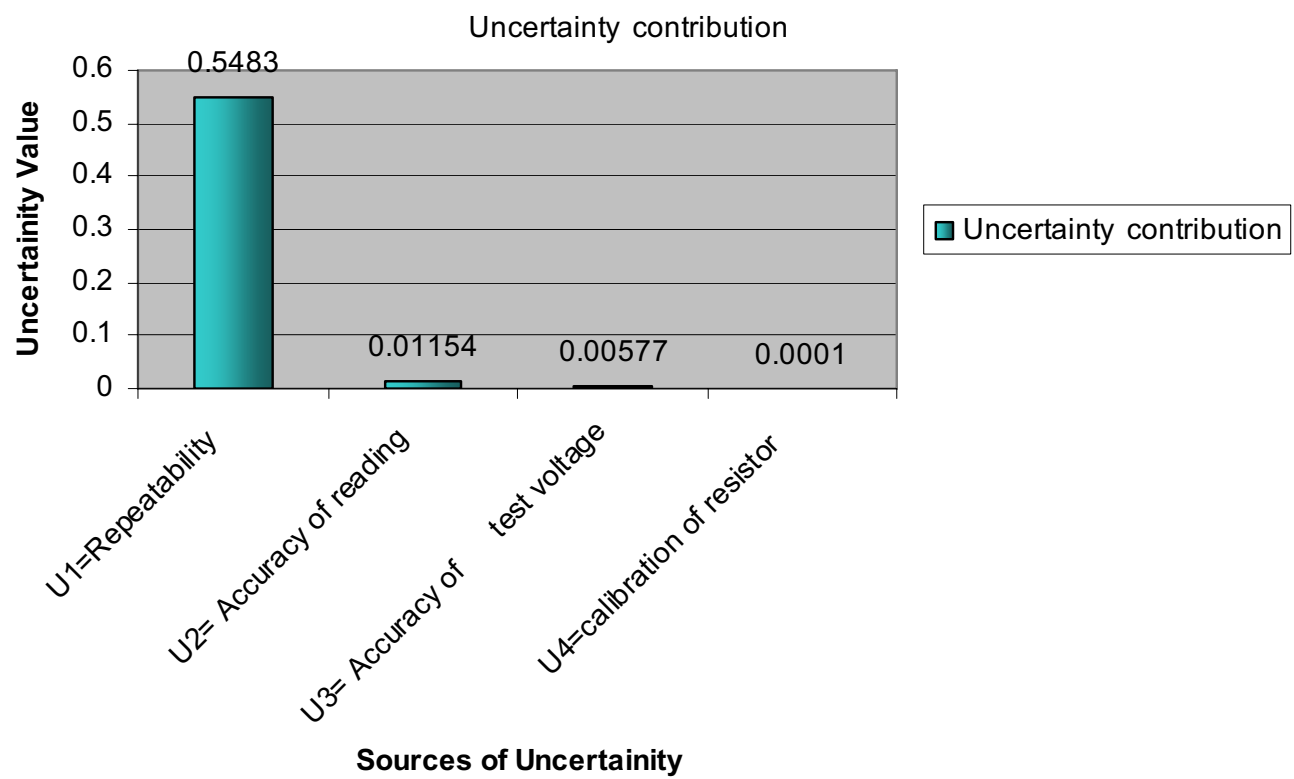

Fig. 8. (Color online) Effects of various factors for resistivity.

Then coverage factor $(K)$ for $U_{\text {eff }}=\infty$ at level of confidence of approximately $95 \%, K=1.96$.

Expanded uncertainty $=0.5483 \times 10^{12} \times 1.96= \pm 1.0966 \times$ $10^{12}$.

Considering coverage factor $K=1.96$ at $95 \%$ confidence level.

Final result $=19.703 \times 10^{12} \pm 1.0966 \times 10^{12}$.

Uncertainty Budget - Refer Table 7.

Uncertainty Contribution - Refer Figure 8.

\subsection{Combine effect analysis of test set up}

Two quality parameters i.e. Tan Delta and resistivity of transformer oil are checked on single equipment setup. The effects of individual parameters on combined uncertainty of measurement is case of resistivity is more as compare to Tan Delta as represented in Table 8.

\section{Conclusion}

Uncertainty of measurement plays vital role for deciding the quality of transformer oil. Selection of improper oil affects the performance of electrical appliances. In case of Tan Delta test uncertainty factor arising from test voltages is affecting more, so proper care should be taken for calibration of instrument and setting of test voltage so that the uncertainty value should get reduced. The main 
Table 7. Uncertainty budget.

\begin{tabular}{|c|c|c|c|c|c|}
\hline Sources & $\begin{array}{c}\text { Probability } \\
\text { type A or type B }\end{array}$ & Std uncertainty $\mathrm{MPa}$ & $\begin{array}{l}\text { Sensitivity } \\
\text { coefficient }\end{array}$ & $\begin{array}{l}\text { Uncertainty } \\
\text { contribution }\end{array}$ & $\mathrm{DOF}$ \\
\hline$U_{1}=$ Repeatability & Normal, type A & $0.5483 \times 10^{12}$ & 1 & $0.5483 \times 10^{12}$ & 9 \\
\hline$U_{2}=$ Accuracy of reading & Rectangular type B & 0.01154 & 1 & 0.01154 & $\infty$ \\
\hline$U_{3}=$ Accuracy of test voltage & Rectangular type B & 0.00577 & 1 & 0.00577 & $\infty$ \\
\hline $\begin{array}{l}U_{4}=\text { calibration of resistor } \\
\text { Expanded uncertainty }\end{array}$ & $\begin{array}{c}\text { Rectangular type B } \\
K=1.96\end{array}$ & 0.00010 & 1 & $\begin{array}{c}0.00010 \\
\pm 1.0966 \times 10^{12}\end{array}$ & $\infty$ \\
\hline
\end{tabular}

Table 8. Effects of individual factors for two tests.

\begin{tabular}{lccccc}
\hline Test & Type-A & & \multicolumn{2}{c}{ Type-B } \\
& Repeatability & Accuracy of reading & Accuracy of test & calibration of capacitor & calibration of resistor \\
& & & voltage & 0.00076 & - \\
Tan Delta & 0.000073 & 0.000057 & 0.00577 & - & 0.00010 \\
Resistivity & $0.5483 \times 10^{12}$ & 0.01154 & 0.00577 & - \\
\hline
\end{tabular}

influence factor in the determination of the uncertainty of measurement in case of resistivity is the variation attributed to the measurand that is the repeatability obtained in the measurements of the studied properties. The operator error which affects repeatability should be minimizing by following the proper procedure of the test. Even if the result of the measurement is not perfect, it is possible to obtain reliable information, since the result of the measurement is associated with its respective uncertainty. This study involves the development of a methodology for determining the result of measurement concerning electrical properties and their respective uncertainties. Such methodology, which has a possible systematic application, is associated with guaranteeing of reliability to the results of the electrical properties, as well as the possibility of Implementation in transformer oil testing laboratories.

Acknowledgements. Authors greatly acknowledged central government India Coal and Oil Testing Lab, Mahagenco Nagpur, India for getting the actual research work for transformer oil in testing lab.

\section{References}

1. L. Hamrick, ESCO Energy Services, Transformer Oil Sampling (2009)

2. Technical Lab manual of Central Coal and oil Testing Lab, Nagpur, India

3. Quality manual of Eltel industries, Banglore, India, www.eltelindustries.com

4. BIPM/IECIIFCC/ISO/OIML/IUPAC, ISBN 9267 101889, 1993-95-Guide to the expression of uncertainty in measurement, technical report by EUROLAB Technical Secretariat, C/o BAM, Unter den Eichen 87, Germany

5. JCGM 100:2008 GUM 1995 with minor corrections, Evaluation of measurement data

6. N.K. Mandavgade, S.B. Jaju, R.R. Lakhe, Evaluation of uncertainty of measurement in tensile testing, Int. J. Eng. Techsci. 2, 221-224 (2011)

7. N.K. Mandavgade, S.B. Jaju, R.R. Lakhe, D.J. Tidke, Mathematical modeling of effects of various factors on uncertainty of measurement in material testing, ASME digital library Proceedings of 2011 International Conference on Mechanical Engineering and Technology, ICMET 2011, London, UK, 2011 